Research Article

\title{
Developing an Empirical Relationship to Predict the Wear Characteristics of Ni-Based Hardfaced Deposits on Nuclear Grade 316LN Austenitic Stainless Steel
}

\author{
S. Gnanasekaran $\mathbb{D D}^{1}{ }^{1}$ Samson Jerold Samuel Chelladurai $\mathbb{D}^{2},{ }^{2}$ G. Padmanaban, ${ }^{3}$ \\ Ramesh Arthanari $\mathbb{D}^{4},{ }^{4}$ and V. Balasubramanian $\mathbb{D}^{3}$ \\ ${ }^{1}$ Department of Mechanical Engineering, Sri Shakthi Institute of Engineering and Technology, Chinniyampalayam, Coimbatore, \\ Tamil Nadu, India \\ ${ }^{2}$ Department of Mechanical Engineering, Sri Krishna College of Engineering and Technology, Coimbatore, Tamilnadu, India \\ ${ }^{3}$ Centre for Materials Joining \& Research (CEMAJOR), Department of Manufacturing Engineering, Annamalai University, \\ Annamalainagar, Tamil Nadu, India \\ ${ }^{4}$ Department of Mechanical Engineering, Chennai Institute of Technology, Tamil Nadu, India
}

Correspondence should be addressed to Samson Jerold Samuel Chelladurai; samsonjeroldsamuel@skcet.ac.in

Received 4 August 2021; Revised 29 September 2021; Accepted 6 October 2021; Published 14 October 2021

Academic Editor: Alicia E. Ares

Copyright (c) 2021 S. Gnanasekaran et al. This is an open access article distributed under the Creative Commons Attribution License, which permits unrestricted use, distribution, and reproduction in any medium, provided the original work is properly cited.

\begin{abstract}
Using the nickel-based Colmonoy 5 hardfacing alloy, components made of austenitic stainless steel (ASS) used in nuclear power plants can be hardfaced. Hardfacing is the process of applying complex and wear-resistant materials to substrates that require abrasion resistance. The tribological characteristics of a reactor-grade material NiCr-B hardfaced deposit were studied and reported in this paper. Hence, in this investigation, an effort has been made to develop empirical relationship to predict weight loss of laser hardfaced Ni-based alloy surface incorporating laser parameters using statistical tools such as design of experiments (DoE) and analysis of variance (ANOVA). The developed empirical relationship can be effectively used to trail the weight loss (wear resistance) of laser hardfaced nickel alloy surfaces by altering laser parameters. This method has proven very effective. A power of $1300 \mathrm{~W}$, powder feed rate of $9 \mathrm{~g} / \mathrm{min}$, travel speed of $350 \mathrm{~mm} / \mathrm{min}$, and defocusing distance of $32 \mathrm{~mm}$ were all combined to achieve a minimum weight loss of 0.0164 grams.
\end{abstract}

\section{Introduction}

The Indian prototype fast breeder reactor (PFBR) is a pooltype liquid sodium-cooled reactor with two independent sodium circuits (primary and secondary heat exchangers), with the intermediate heat exchanger (IHX) allowing thermal contact between the main pool and the auxiliary circuit. Thermal exchange occurs between the IHX and a steam generator (SG), which powers conventional steam turbines via the use of auxiliary sodium circuits. In PFBR, austenitic stainless steel (AISI 316LN) is the primary structural material (e.g., main vessel, inner vessel, grid plate, and primary pipework, among others), with a nitrogen content of $0.06-0.08$ percent and service temperatures exceeding $800^{\circ} \mathrm{F}[1]$. In order to transfer heat between the primary and secondary heat exchangers, liquid sodium is used as a transfer medium. During normal operation, the minimum sodium temperature in the primary pool is $400^{\circ} \mathrm{C}$, and the mean above-core temperature is $550^{\circ} \mathrm{C}$. The sodium temperatures in the secondary circuit range between 355 and $525^{\circ} \mathrm{C}$ at their lowest and highest points, respectively. The liquid sodium coolant acts as a decreasing specialist, allowing the self-protective layer that forms on the ASS external surface of the sodium needs to be evacuated and removed. To improve self-welding and galling resistance, a common technique is to face these components with nickel- 
or cobalt-based alloys. The induced Co60 radioactive isotopes are generated in nuclear reactor environment $[2,3]$ was discovered in stellite Co-based alloys, which are used as a hardfacing material in high-temperature applications. Since the Colmonoy grades include substantial quantities of chromium and boron, they may be a strong replacement in terms of adhesive wear resistance for cobased stellite alloys. This is because these elements are highly concentrated in the alloy $[4,5]$. Colmonoy alloys have a greater hardness than stellite. The existence of chromium carbide $(\mathrm{CrC})$ and chromium boride $(\mathrm{CrB})$ in the deposit is ascribed to this, as opposed to carbide precipitates exclusively in stellite and chromium borides found in the deposit [6].

A material's wear resistance is a mechanical property that must be present to resist surface damage when moving dynamically across surfaces $[3,7,8]$. During tribology testing, the physical, chemical, physical, and mechanical characteristics of the wear produced cavities vary in response to the changing conditions. The change in the shape of the wear clot may have an impact on the amount of frictional force that is applied immediately. Wear procedures may be divided into four types using steel-based alloys: adhesive wear, abrasive wear, oxidation wear, and plastic extrusion [9-12]. In generally, the relationship between a material's hardness and its wear resistance is inverse. This reservoir has a greater wear resistance than stainless steel, resulting in longer service life for FBR components. Hardfacing is a frequently used method for increasing the lifetime of heavy load components that has been widely known technic. However, even though hardfacing alloys have been developed to have the optimal chemistry and microstructure for certain service conditions, dilution with a substrate changes their physical properties over a relatively significant percentage of their whole thickness.

However, despite the fact that this alloy has superior mechanical characteristics, the friction and wear caused by this alloy have not yet been well investigated and understood as a function of sliding distance. The parameters of the hardfacing process affect the quality of the deposits significantly. Only a few research studies were performed to understand better the effect on individual wear characteristics of laser process parameters. In this study, an effort has been made to develop an empirical connection to forecast wear resistance of hardfaced alloy deposits utilizing statistical methods, such as experimental design, variance analysis, and regression analysis, integrating major laser surface characteristics.

\section{Experimental Work}

2.1. Substrate (Base Metal) and Hardfaced Powder (Colmonoy 5) Properties. It is essential to highlight that in this study, the substrate (316LN stainless steel) is nucleic stainless steel that is widely used for, among other uses, valves, valve cones, and spindles. The chemical composition of the base metal was obtained using a vacuum spectrometer (make: ARL USA; Model3460). Sparks were ignited at various locations of the base metal sample, and their spectrum was analyzed for the estimation of alloying elements. The chemical compositions of the substrate material and hardfaced powder are shown in
Tables 1 and 2, respectively. The austenitic AISI 316LN stainless-steel rolling plates with a thickness of $12 \mathrm{~mm}$ served as the foundation for this structure. Heating the substrate to $400 \mathrm{C}$ was done in order to alleviate internal tensions and slow down the cooling rate in order to prevent the development of fractures after the deposition process was completed. The hardfacing tests were performed by using an automated disk laser machine [13, 14].

The formation of a single layer, as shown in Figure 1, was the foundation for the research. Pure argon gas (99.9\% purity) was used in the experiment to protect the gas and to feed the powder gas. According to the manufacturer, the deposit had an average thickness of $0.8-2 \mathrm{~mm}[15,16]$. To determine the realistic range of operations of the laser hardfacing parameters (Table 3), a significant number of trial tests have been conducted, each with different parameters, all of which remaining constant. Table 4 shows the most important components and their relative significance. The experimental design (DoE) method was used in order to reduce the quantity of experimental work. In order to minimize experimental conditions, a central composite rotatable design matrix with four variables and five levels was utilized. We were able to construct fourfactor factorial designs with 16 points, eight-star points, and six center points using the design matrix (Table 5), including 30 sets of coded conditions. The upper and lower limits of the parameters are referred to the digits +2 and -2 , respectively, in the code. This formula may be used to calculate the intermediate level coded values which are as follows:

$$
X i=2 X-\frac{\left(X_{\max }+X_{\min }\right)}{\left(X_{\max }-X_{\min }\right)},
$$

where $A$ variable from $\mathrm{X}_{\min }$ to $\mathrm{X}_{\max }$ must be coded with $X$.

The deposits were made in line with the design matrix requirements and were made randomly to avoid systemic error from entering results. Figure 2 displays a sample of the produced deposits. For the metallography study, the deposits were chopped into small pieces while they were hardfaced. The dry slide wear resistance at room temperature was determined using a pin-on-disk setup [17, 18]. Pins are chopped from a thick ASS plate using electric discharge equipment in order to provide the required wear specimens for testing. Rugged test specimens were polished with a 1000 micron $\mathrm{SiC}$ sheet and then with $\mathrm{Al}_{2} \mathrm{O}_{3}$ to achieve the necessary roughness (RA) value of just under 0.25 micron.

Wear rate and coefficient of friction (COF) of the hardfaced surfaces were evaluated using the pin-on-disc wear test as per ASTM G99-05. Specimens were extracted from the hardfaced stainless-steel plate as per stranded dimensions of $10 \mathrm{~mm}$ diameter and $20 \mathrm{~mm}$ length pin spinning disk slide at $55 \mathrm{~mm}$ diameter with a pitch circle of $45 \mathrm{~mm}$ diameter and linear speed of $0.1 \mathrm{~m} / \mathrm{s}$. The specimens were evaluated at room temperature under normal load conditions with a typical load of $50 \mathrm{~N}[19,20]$. After each test, the specimen's weight loss was used to determine the specimen's wear resistance. All experiments have been repeated to verify that they are reasonably reproducible. Before and after each trial, the specimen was carefully cleaned in alcohol and gently dried, and the weight loss was quantified to an accuracy of $0.001 \mathrm{mg}$ before and after each test. 
TABLE 1: Substrate material chemical composition in wt $\%$.

\begin{tabular}{lccccccccccc}
\hline $\mathrm{C}$ & $\mathrm{Ni}$ & $\mathrm{Cr}$ & $\mathrm{Mo}$ & $\mathrm{Si}$ & $\mathrm{Mn}$ & $\mathrm{Cu}$ & $\mathrm{Nb}$ & $\mathrm{S}$ & $\mathrm{P}$ & $\mathrm{W}$ & $\mathrm{Fe}$ \\
\hline 0.0200 & 12.550 & 17.270 & 2.350 & 0.290 & 1.690 & 0.0470 & 0.020 & 0.0270 & 0.026 & 0.03 & $\mathrm{Bal}$ \\
\hline
\end{tabular}

TABLE 2: Colmonoy 5 hardfaced power chemical composition in wt \%.

\begin{tabular}{lcccccc}
\hline $\mathrm{C}$ & $\mathrm{Fe}$ & $\mathrm{Cr}$ & $\mathrm{Si}$ & $\mathrm{B}$ & $\mathrm{O}$ & $\mathrm{Ni}$ \\
\hline 0.410 & 3.100 & 10.440 & 4.020 & 2.260 & 0.030 & Balance \\
\hline
\end{tabular}

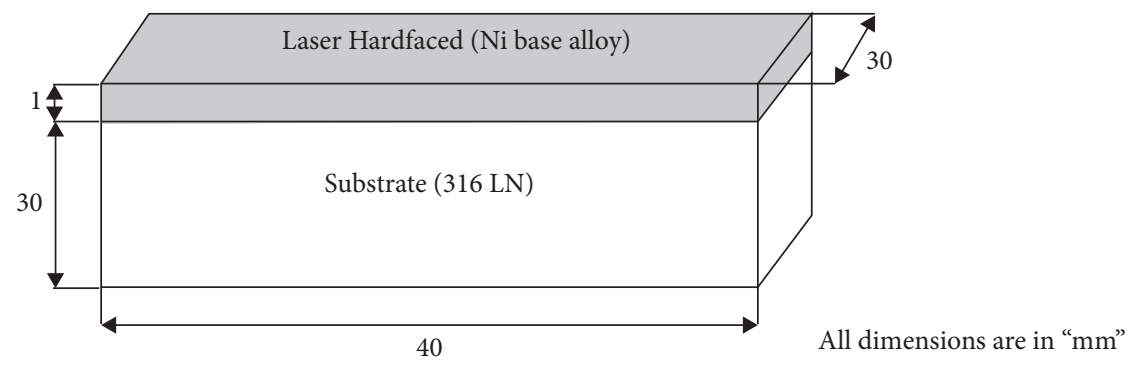

FIgURE 1: Schematic diagram of single-layer hardfacing.

TABLE 3: The variables of the process parameters and their operating range.

\begin{tabular}{|c|c|c|c|c|c|c|c|c|}
\hline \multirow{2}{*}{ S.No } & \multirow{2}{*}{ Process parameters } & \multirow{2}{*}{ Symbols } & \multirow{2}{*}{ Units } & \multicolumn{5}{|c|}{ Levels } \\
\hline & & & & -2 & -1 & 0 & 1 & 2 \\
\hline 1 & Laser power & $P$ & Watts & 1100 & 1300 & 1500 & 1700 & 1900 \\
\hline 2 & Rate of powder feed & $\mathrm{F}$ & Gram/min & 3 & 5 & 7 & 9 & 11 \\
\hline 3 & Travel speed & $\mathrm{T}$ & $\mathrm{mm} / \mathrm{min}$ & 300 & 350 & 400 & 450 & 500 \\
\hline 4 & Defocusing distance & $\mathrm{D}$ & $\mathrm{mm}$ & 17 & 22 & 27 & 32 & 37 \\
\hline
\end{tabular}

TABLE 4: Macrostructure investigation to determine the laser hardfacing's operating range.

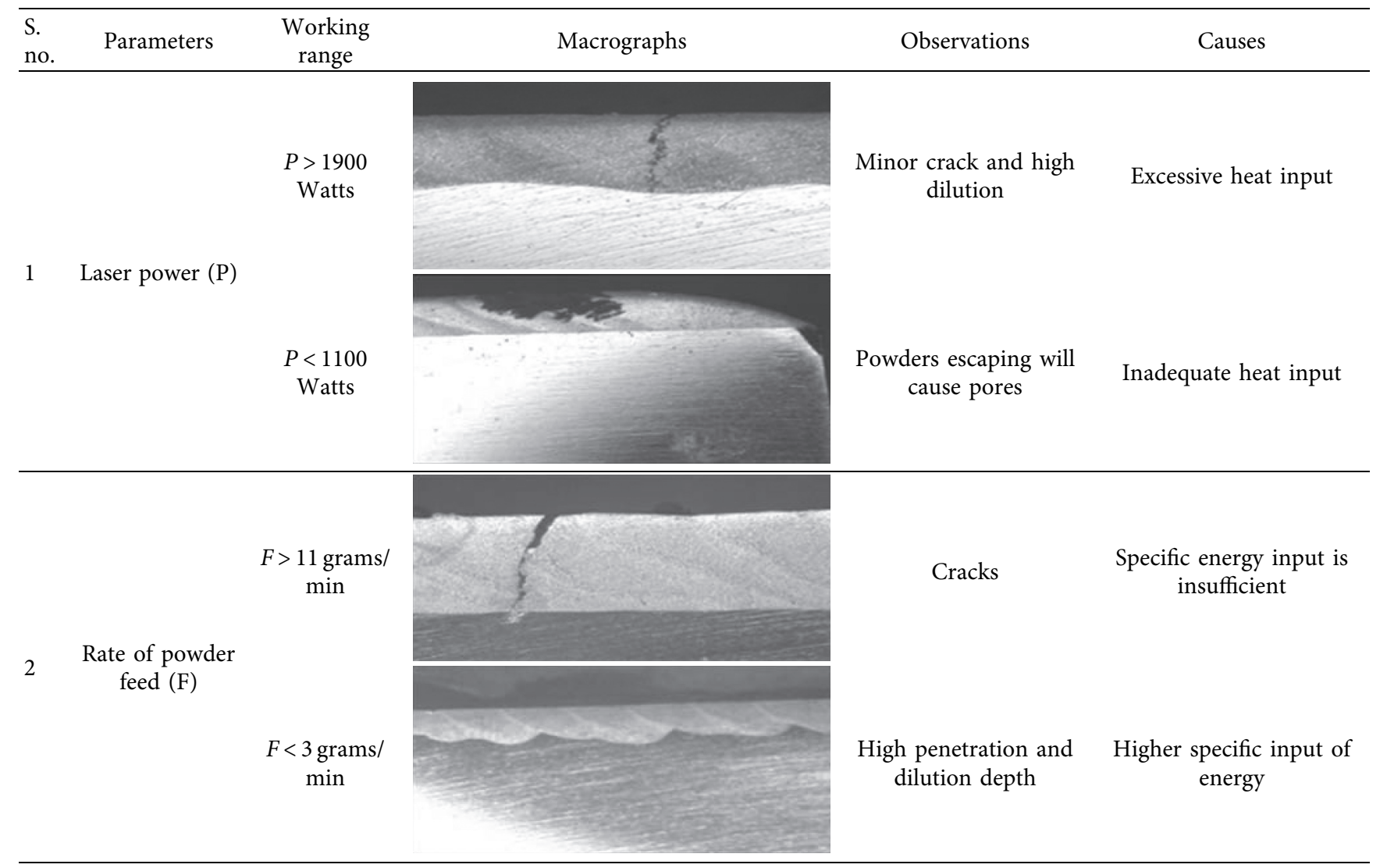


TABle 4: Continued.

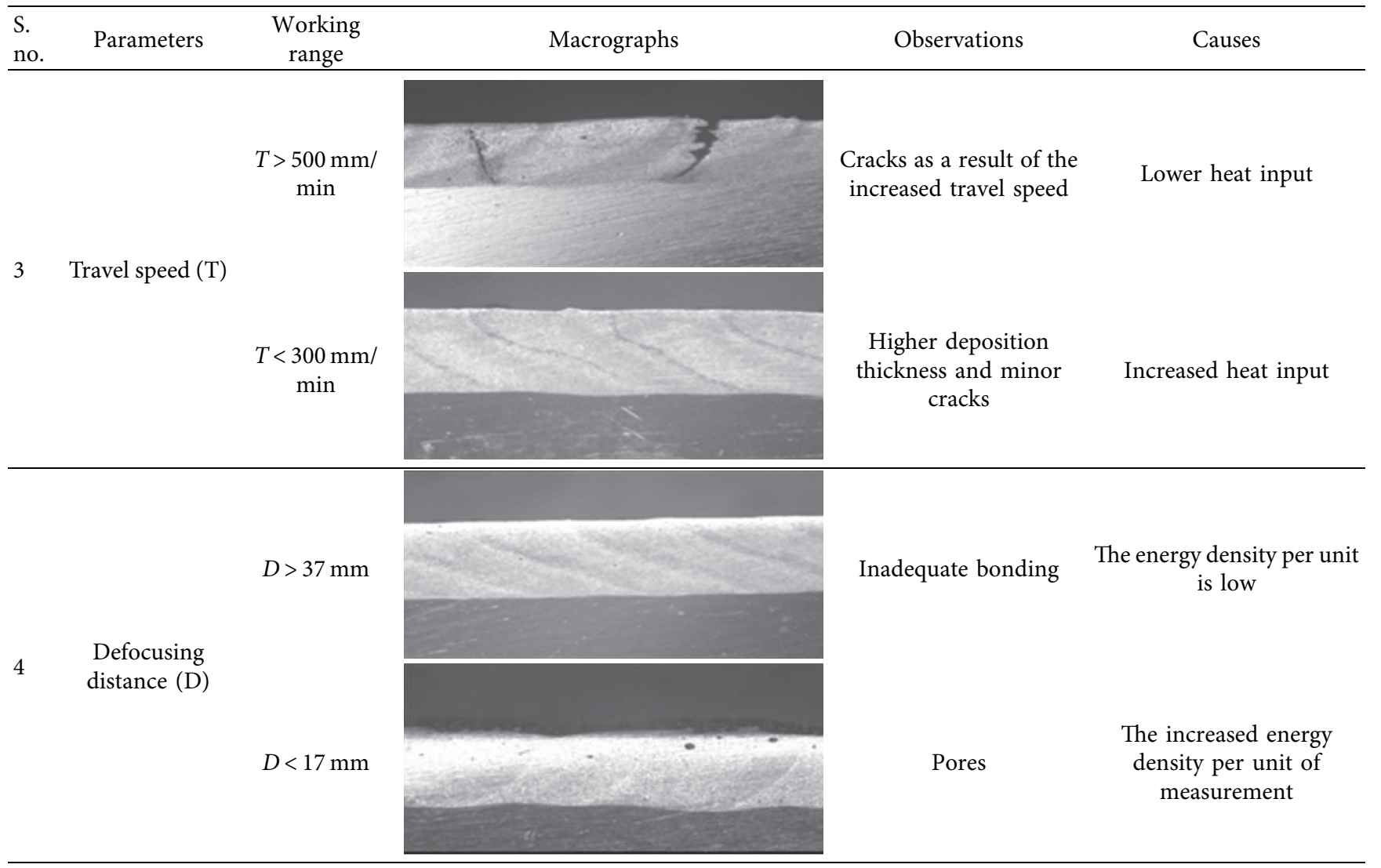

TABle 5: Pin-on-disc wear test parameters

\begin{tabular}{lc}
\hline Parameter & Values \\
\hline Pin size $(\mathrm{mm})$ & Diameter $=10$, length $=20$ \\
Disc size $(\mathrm{mm})$ & Diameter $=120$, thickness $=8$ \\
Load $(\mathrm{N})$ & 50 \\
Velocity range $(\mathrm{m} / \mathrm{s})$ & 1 \\
Sliding distance $(\mathrm{m})$ & 500 \\
\hline
\end{tabular}

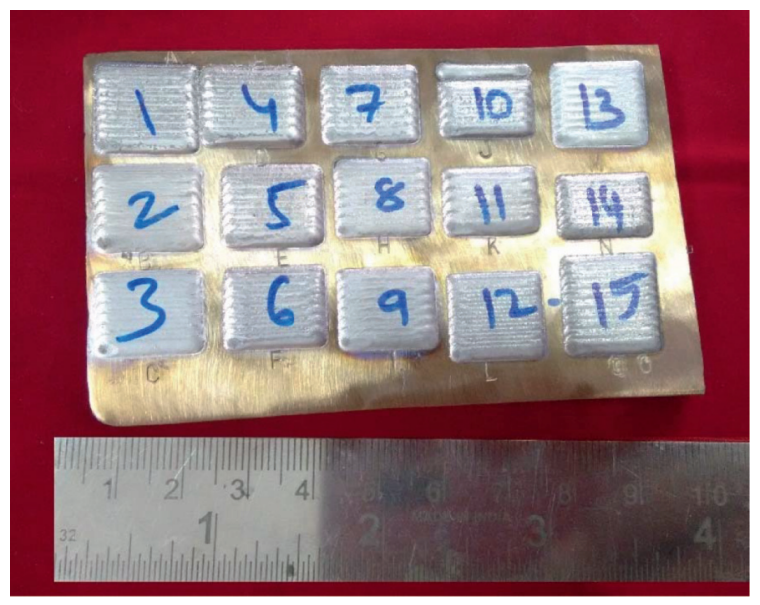

FIgURE 2: Fabricated deposits.

\section{Developing an Empirical Relationship}

In the present work, weight loss is influenced by the laser hardfacing process parameters such as laser power $(Q)$, travel speed $(T)$, rate of powder feed $(F)$, and defocusing distance $(D)$, and it may be stated as follows $[9,21,22]$ :

weight loss of laser hard faced deposit $(\mathrm{W})=f(P, F, T, D)$.

It is provided by the second-order polynomial regression equation that is used to describe the response surface $Y$ as follows:

$$
Y=b_{o}+\sum b_{i} x i+\sum b_{i} x i_{2}+\sum b i j x i x j .
$$

The following is an example of a polynomial expression:

$$
\begin{aligned}
W=b_{o} & +b_{1}(P)+b_{2}(F)+b_{3}(T)+b_{4}(D)+b_{12}(P F) \\
& +b_{13}(P T)+b_{14}(P D)+b_{23}(F T)+b_{24}(F D) \\
& +b_{11}\left(P^{2}\right)+b_{22}\left(F^{2}\right)+b_{33}\left(T^{2}\right)+b_{44}\left(D^{2}\right)+\text { grams. }
\end{aligned}
$$

Bo represents the mean value of the response, whereas b1, b2, b3, b4, and b44 represent linear relations and square relations of variables, respectively. The coefficient value was estimated with the help of the Design Expert 7 program at a $95 \%$ level of confidence. The implication of each coefficient is 
determined using the student's $t$-test and the $P$ values for each coefficient. When the value of "Prob $>F$ " is less than 0.050 , it implies that the model terms are statistically significant ( $P$ 0.05). The words P, F, T, D, PF, PT, PD, FD, TD, and $\mathrm{F} 2$ are the most important in this context. The final empirical connection was built only based on this coefficient. The last empirical affiliation of Ni-based hardfaced deposits produced after that wear test was carried out to find the wear resistance in weight loss and is shown in Table 6 [23].

$$
\begin{aligned}
\text { Weigh loss }= & {\left[\begin{array}{r}
-0.10071+1.42307 E-0.04 *(P)-0.010069 *(F)+6.00779 E-004 *(T)-4.22966 E-003 *(D)+ \\
2.67969 E-006 *(P * F)-4.80313 E-007 *(P * T)+7.51875 E-007 *(P * D)-1.39375 E-006 *(F * T)+1.59062 E-004 *(F * D)+4.86250 E-006 \\
*(T * D)+5.54427 E-009 *\left(P^{2}\right)+1.60677 E-005 *\left(F^{2}\right)+7.08333 E-010 *\left(T^{2}\right)-3.42917 E-006 *\left(D^{2}\right)
\end{array}\right] } \\
& \cdot \text { grams }^{\prime \prime} R_{2}-0.906^{\prime \prime} .
\end{aligned}
$$

The appropriateness of the relationship mentioned above is determined via the use of analysis of variance (ANOVA). The results of the ANOVA test are shown in Table 6; the required confidence level was set at 95 percent in this case. It is possible to regard the connection to be satisfactory. The calculated value of the fraction $\mathrm{F}$ of both the connection established must not exceed the tabular value of the ratio $\mathrm{F}$ for the necessary confidence to be able to evaluate that model sufficiently [24]. Fisher's F test, the probability is extremely low, indicates that the regression model has a very high level of significance. The determination coefficient is used to determine the model's overall goodness of fit (R2). According to the findings, the determination coefficient in response was calculated at 0.98 , showing that $98 \%$ of the research values support the compatibility with model predictions [25].

In most of the situations, the signal-to-noise ratio greater than 4 is desirable. During this study, the signal-to-noise ratio was 30.969 , which suggests that the signal is sufficient. This model may be utilized to travel through the design space. Figure 3 depicts the correlation graph between the expected and actual hardness of hardfaced Ni deposits. This implies that the gap in both actual and expected weight reduction is minimal. Table 7 shows the difference between the actual and anticipated weight reduction. Figure 4 depicts a single-track deposit with a $50 \%$ track overlap on the deposit [26-28].

$\mathrm{R} 2$ should always be between 0 and 1 . If a model is statistically sound, it should have an R2 value close to or greater than 1.0. The phrase with significant terms is then rebuilt using the updated $\mathrm{R} 2$ value. The Adj. $R 2=0.961$ value is also outstanding, suggesting that the model is highly relevant. The R2 score for prediction is 0.906 , indicating that the model can account for $90.6 \%$ of the variability in predicting outcomes. This is in reasonable accord with the Adj. R2 of 0.961. The coefficient of variation was determined to be as low as 3.97 , suggesting a negligible discrepancy between experimental and predicted values $[29,30]$.

To construct the joint at $1300 \mathrm{~W}$, a rate of powder feed of nine grams per minute, a travel speed of three hundred and fifty millimetres per minute, and a defocusing distance of thirty millimetres per minute, the following parameters were used: the specimen's cross section (Figure 5(a)) demonstrates that there are no surface fractures or indications of lack of adhesion in the specimen. When the track was metallographically inspected, it was discovered to have a dendritic structure that was uniformly dispersed across it with a continuous interface (Figure 5(b)) [31,32]. The solid solution phase of $\mathrm{Ni}$ in the form of a dendrite is the microstructural component that dominates the deposit's microstructure. Additionally, microstructure reveals the presence of a large number of precipitate particles, especially chromium-rich carbides, in the sample (Figure 5(b)). Colmonoy 5 coatings are comprised of three major components such as $\mathrm{Cr}$-rich precipitates such as $\mathrm{CrB}$ and $\mathrm{CrC}$, $\mathrm{Ni}$ solid solution dendrites, and Ni-B-Si binary and ternary eutectic phases such as $\mathrm{NiB}$ and NiSi (Figure 6) [13]. Once at the interface $(500 \mathrm{HV})$ with base metal, the hardness values remain constant until near the deposit's top ( $825 \mathrm{HV})(230$ HV). Perhaps the alloys' hardness is linked to the occurrence of hard phases such as Ni3B and Cr23C6. The presence of a uniformly distributed mixture of complex carbides and borides precipitates is believed to be responsible for the deposits' enhanced hardness. Table 8 shows the confirmation test results. It shows error in percentage and actual weight loss, and forecast weight loss is also conformed $[33,34]$.

To evaluate wear resistance, the substrate and deposited surfaces were subjected to a pin-on-disc wear test. The wear test parameters are shown in Table 5. At room temperature, the wear tests were performed in a self-mating setting with no external mating. It is evident that the rate of wear increases rapidly during the first stage of the wear test. The asperities on the specimens' worn surfaces, which result in the actual contact area of the friction pair being smaller than its nominal counterpart, are attributed to the material's increase in frictional resistance. At first, the asperities on the test piece's surface flake off throughout the run, and the wear rate increases as the test continues. After 30 minutes, when the sliding time is extended, the wear rate decreases, and this tendency continues. Wear resistance is enhanced in materials such as chromium borides (2575 VHN) and chrome carbides (1670 VHN) due to the complex phases in the coating serving as protective layers during the wear test $[35,36]$. 
TABLE 6: The design matrix and the experiment findings.

\begin{tabular}{|c|c|c|c|c|c|c|c|c|c|}
\hline \multirow{2}{*}{ Exp no. } & \multicolumn{4}{|c|}{ Coded values } & \multicolumn{4}{|c|}{ Actual values } & \multirow{2}{*}{ Weight loss (grams) } \\
\hline & $\mathrm{P}$ & $\mathrm{F}$ & $\mathrm{T}$ & $\mathrm{D}$ & P (Watts) & F (gram/min) & $\mathrm{T}(\mathrm{mm} / \mathrm{min})$ & $\mathrm{D}(\mathrm{mm})$ & \\
\hline 1 & -1 & -1 & -1 & -1 & 1300 & 5 & 350 & 22 & 0.0322 \\
\hline 2 & 1 & -1 & -1 & -1 & 1700 & 5 & 350 & 22 & 0.04141 \\
\hline 3 & -1 & 1 & -1 & -1 & 1300 & 9 & 350 & 22 & 0.0183 \\
\hline 4 & 1 & 1 & -1 & -1 & 1700 & 9 & 350 & 22 & 0.0313 \\
\hline 5 & -1 & -1 & 1 & -1 & 1300 & 5 & 450 & 22 & 0.039 \\
\hline 6 & 1 & -1 & 1 & -1 & 1700 & 5 & 450 & 22 & 0.0291 \\
\hline 7 & -1 & 1 & 1 & -1 & 1300 & 9 & 450 & 22 & 0.028 \\
\hline 8 & 1 & 1 & 1 & -1 & 1700 & 9 & 450 & 22 & 0.01826 \\
\hline 9 & -1 & -1 & -1 & 1 & 1300 & 5 & 350 & 32 & 0.0238 \\
\hline 10 & 1 & -1 & -1 & 1 & 1700 & 5 & 350 & 32 & 0.0328 \\
\hline 11 & -1 & 1 & -1 & 1 & 1300 & 9 & 350 & 32 & 0.0164 \\
\hline 12 & 1 & 1 & -1 & 1 & 1700 & 9 & 350 & 32 & 0.0322 \\
\hline 13 & -1 & -1 & 1 & 1 & 1300 & 5 & 450 & 32 & 0.0362 \\
\hline 14 & 1 & -1 & 1 & 1 & 1700 & 5 & 450 & 32 & 0.0279 \\
\hline 15 & -1 & 1 & 1 & 1 & 1300 & 9 & 450 & 32 & 0.0268 \\
\hline 16 & 1 & 1 & 1 & 1 & 1700 & 9 & 450 & 32 & 0.0249 \\
\hline 17 & -2 & 0 & 0 & 0 & 1100 & 7 & 400 & 27 & 0.0262 \\
\hline 18 & 2 & 0 & 0 & 0 & 1900 & 7 & 400 & 27 & 0.0317 \\
\hline 19 & 0 & -2 & 0 & 0 & 1500 & 3 & 400 & 27 & 0.0368 \\
\hline 20 & 0 & 2 & 0 & 0 & 1500 & 11 & 400 & 27 & 0.0198 \\
\hline 21 & 0 & 0 & -2 & 0 & 1500 & 7 & 300 & 27 & 0.0277 \\
\hline 22 & 0 & 0 & 2 & 0 & 1500 & 7 & 500 & 27 & 0.0283 \\
\hline 23 & 0 & 0 & 0 & -2 & 1500 & 7 & 400 & 17 & 0.0304 \\
\hline 24 & 0 & 0 & 0 & 2 & 1500 & 7 & 400 & 37 & 0.0250 \\
\hline 25 & 0 & 0 & 0 & 0 & 1500 & 7 & 400 & 27 & 0.0287 \\
\hline 26 & 0 & 0 & 0 & 0 & 1500 & 7 & 400 & 27 & 0.0279 \\
\hline 27 & 0 & 0 & 0 & 0 & 1500 & 7 & 400 & 27 & 0.0287 \\
\hline 28 & 0 & 0 & 0 & 0 & 1500 & 7 & 400 & 27 & 0.0279 \\
\hline 29 & 0 & 0 & 0 & 0 & 1500 & 7 & 400 & 27 & 0.0269 \\
\hline 30 & 0 & 0 & 0 & 0 & 1500 & 7 & 400 & 27 & 0.0297 \\
\hline
\end{tabular}

Color points by value of Weight loss:

0.04141
0.0164

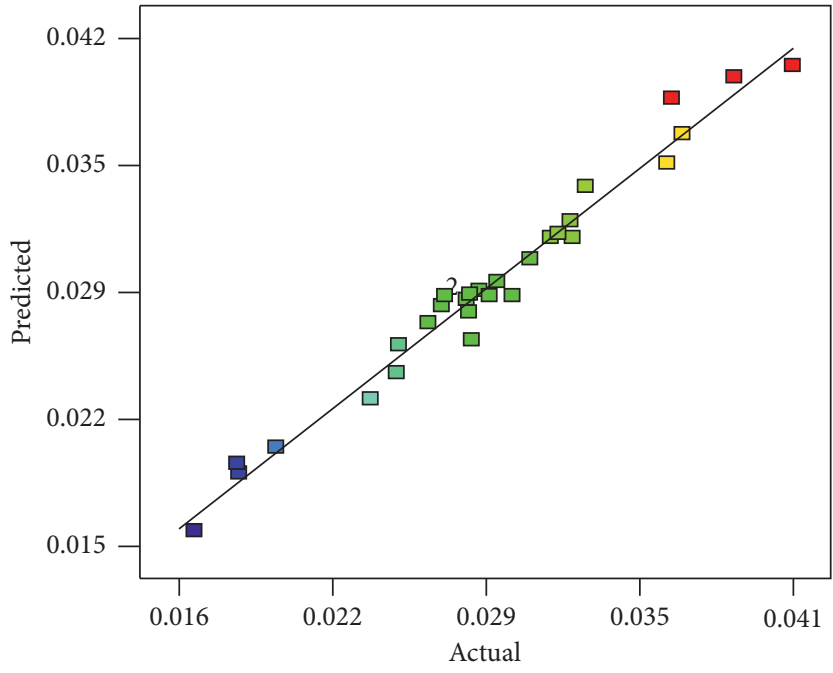

Figure 3: Correlation graph. 
TABle 7: ANOVA test results.

\begin{tabular}{lcccccc}
\hline Source & Sum of squares & Degree of freedom & Mean square & $F$ value & $P$ value (prob $>F$ ) & Whether significant or not \\
\hline Model & $9.662 E-4$ & 14 & $6.901 E-5$ & 140.87 & $<0.0001$ & Significant \\
$\mathrm{P}$ & $4.053 E-5$ & 1 & $4.053 E-5$ & 82.74 & $<0.0001$ & Significant \\
$\mathrm{F}$ & $4.437 E-4$ & 1 & $4.437 E-4$ & 905.69 & $<0.0001$ & Significant \\
$\mathrm{T}$ & $5.042 E-10$ & 1 & $5.042 E-10$ & 10.52 & 0.0048 & Not significant \\
$\mathrm{D}$ & $2.487 E-5$ & 1 & $2.487 E-5$ & 50.76 & $<0.0001$ & $<0.0001$ \\
$\mathrm{PF}$ & $2.538 E-5$ & 1 & $2.538 E-5$ & 51.80 & $<0.0001$ \\
$\mathrm{PT}$ & $3.409 E-4$ & 1 & $3.409 E-4$ & 695.82 & 0.0057 \\
$\mathrm{PD}$ & $5.096 E-6$ & 1 & $5.096 E-6$ & 10.40 & 0.0814 \\
$\mathrm{FT}$ & $1.710 E-6$ & 1 & $1.710 E-6$ & 3.49 & $<0.0001$ \\
$\mathrm{FD}$ & $5.059 E-5$ & 1 & $5.059 E-5$ & 103.27 & $<0.0001$ \\
$\mathrm{TD}$ & $3.150 E-5$ & 1 & $3.150 E-5$ & 64.30 & 0.0968 \\
$\mathrm{P}^{2}$ & $1.538 E-6$ & 1 & $1.538 E-6$ & 3.14 & 0.0519 \\
$\mathrm{~F}^{2}$ & $1.724 E-7$ & 1 & $1.724 E-7$ & 0.35 & 0.9018 \\
$\mathrm{~T}$ & $7.715 E-9$ & 1 & $7.715 E-9$ & 0.016 & 0.6044 \\
$\mathrm{D}^{2}$ & $1.372 E-7$ & 1 & $1.372 E-7$ & 0.28 & \\
Residual & $7.348 E-6$ & 15 & $4.899 E-7$ & & 0.1399 \\
Lack of fit & $6.209 E-6$ & 10 & $6.209 E-7$ & 2.73 & Not significant \\
Pure error & $1.139 E-6$ & 5 & $2.277 E-7$ & Pred. $\mathrm{R}^{2}$ & 0.9616 \\
Cor total & $9.735 E-4$ & 29 & & Press & $3.741 E-5$ \\
Std. deviation & $6.999 E-4$ & & & Mean & 0.028 \\
$\mathrm{R}^{2}$ & 0.9925 & & & C.V \% & 2.45 \\
Adj. R2 & 0.9854 & & Adeq. precision & 30.969
\end{tabular}

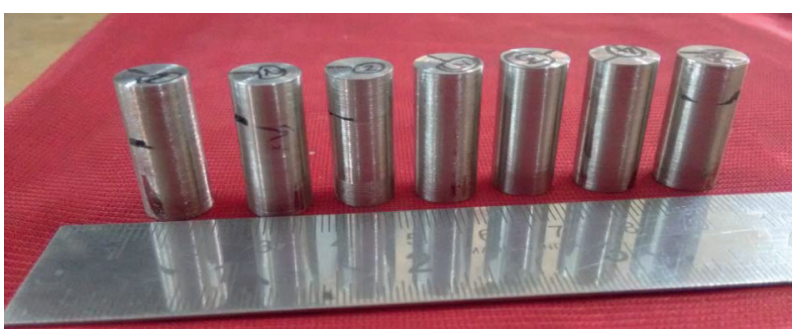

Figure 4: Pin-on-disc samples extracted from laser hardfaced deposit.

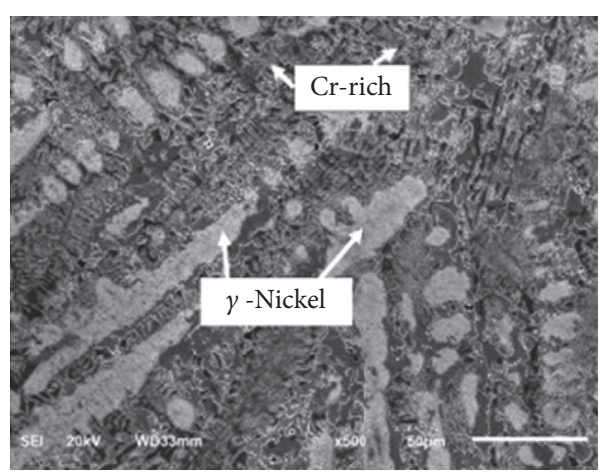

(a)

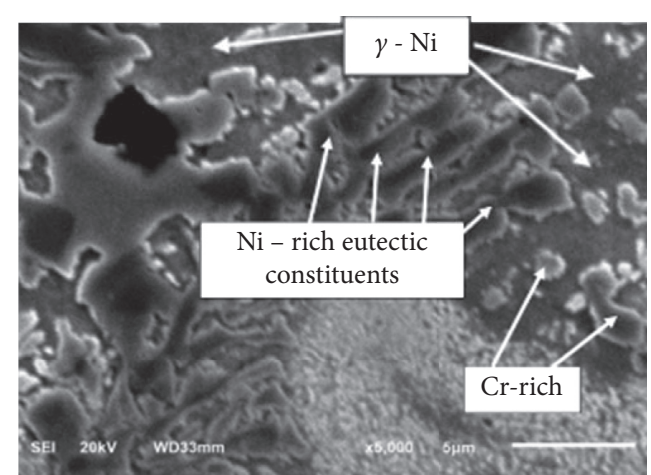

(b)

FIGURE 5: Scanning electron micrograph of laser hardfaced deposit. 
Top surface of wear test specimen

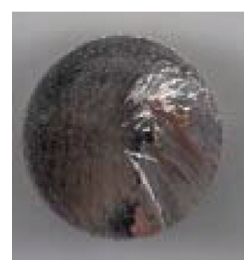

Top surface of wear test specimen

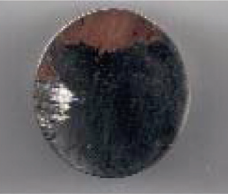

Top surface of wear test specimen

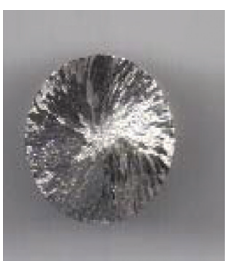

Co-efficient of frication graph

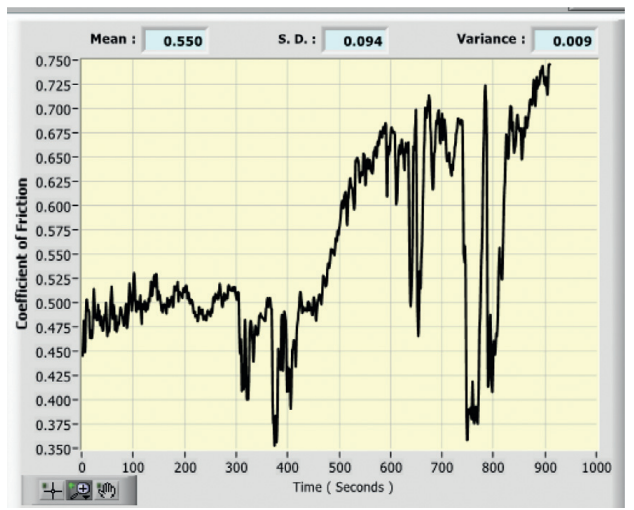

(a)

Co-efficient of frication graph

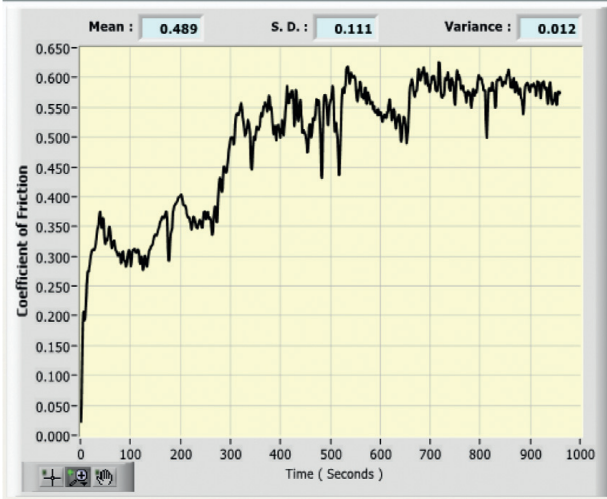

(b)

Co-efficient of frication graph

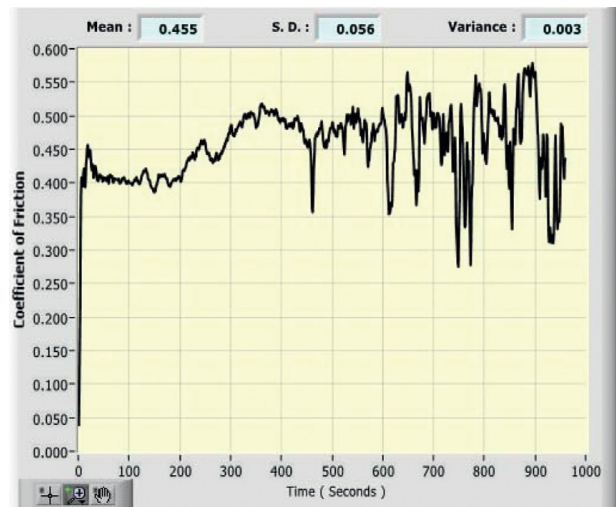

(c)
SEM Image

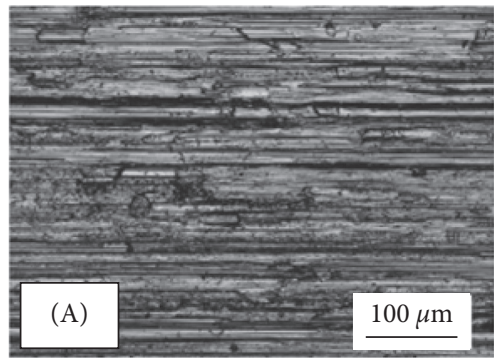

SEM Image

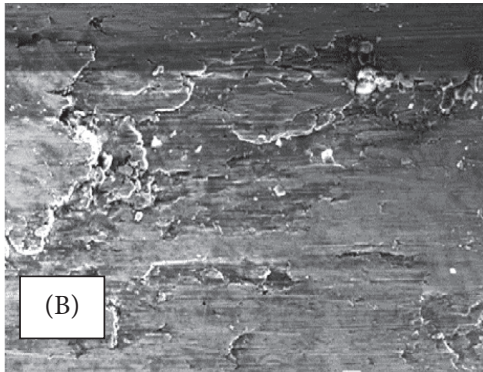

SEM Image

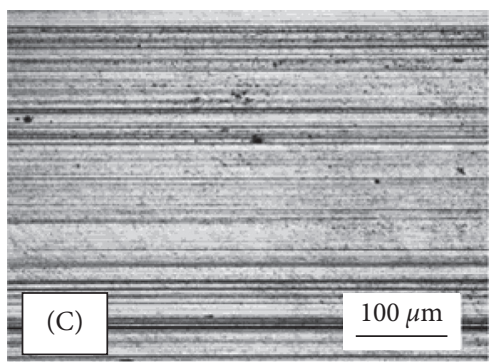

Figure 6: Microscope image of worn surface: (a) substrate; (b) Sample 2; (c) Sample 8. 
TABLE 8: Confirmation test results.

\begin{tabular}{lccccccc}
\hline S. no. & Power $(\mathrm{W})$ & $\begin{array}{c}\text { Rate of powder } \\
\text { feed }(\mathrm{g} / \mathrm{min})\end{array}$ & $\begin{array}{c}\text { Travel speed } \\
(\mathrm{mm} / \mathrm{min})\end{array}$ & Defocusing distance $(\mathrm{mm})$ & Real weight loss in gram & $\begin{array}{c}\text { Forecast weight } \\
\text { loss in gram }\end{array}$ & $\begin{array}{c}\text { Error in } \\
\text { percentage } \%\end{array}$ \\
\hline 01 & 1100 & 4 & 325 & 20 & 0.0307 & 0.0296 & 3.58 \\
02 & 1400 & 6 & 400 & 26 & 0.2728 & 0.2800 & -2.63 \\
03 & 1800 & 8 & 470 & 30 & 0.2802 & 0.2715 & 3.10 \\
\hline
\end{tabular}

\section{Conclusions}

(1) It was possible to predict the hardness of nickelbased hardfaced deposits on 316LN austenitic stainless-steel substrates using an empirical model that took into account laser properties. This relationship was established and tested.

(2) It was possible to obtain a maximum hardness of 820 HV by employing a power of $1300 \mathrm{~W}$, a powder feed rate of $9 \mathrm{~g} / \mathrm{min}$, a travel speed of $350 \mathrm{~mm} / \mathrm{min}$, and a defocusing distance of $32 \mathrm{~mm}$, all of which were combined.

(3) Among the four laser factors examined, the rate of powder feed (as measured by the $\mathrm{F}$ value) has the most significant impact on hardness, followed by laser power, defocusing distance, and travel speed, in that order.

\section{Data Availability}

The data used to support the findings of this study are included within the article.

\section{Conflicts of Interest}

The authors declare that there are no conflicts of interest regarding the publication of this paper.

\section{References}

[1] S. L. Mannan, S. C. B. Chetal, and S. B. Bhoje, Materials R\&D for Prototype Fast Breeder Reactor, S. L. Mannan and M. D. Mathew, Eds., Indira Gandhi Centre for Atomic Research, Kalpakkam, India, 2003.

[2] G. Chakraborty, S. K. Albert, and A. K. Bhaduri, "Effect of dilution and cooling rate on microstructure and magnetic properties of Ni base hardfacing alloy deposited on austenitic stainless steel," Materials Science and Technology, vol. 28, no. 2, pp. 454-459, 2012.

[3] A. K. Bhaduri, R. Indira, S. K. Albert, B. P. S. Rao, S. C. Jain, and S. Asokkumar, "Selection of hardfacing material for components of the Indian Prototype Fast breeder reactor," Journal of Nuclear Materials, vol. 334, no. 2-3, pp. 109-114, 2004.

[4] N. Jeyaprakash and C.-H. Yang, "Comparative study of $\mathrm{NiCrFeMoNb/FeCrMoVC} \mathrm{laser} \mathrm{cladding} \mathrm{process} \mathrm{on} \mathrm{nickel-}$ based superalloy," Materials and Manufacturing Processes, vol. 35, no. 12, pp. 1383-1391, 2020.

[5] N. Jeyaprakash, CH. Yang, M. Duraiselvam, and S. Sivasankaran, "Comparative study of laser melting and preplaced $\mathrm{Ni}-20 \% \mathrm{Cr}$ alloying over nodular iron surface," $\mathrm{Ar}$ chives Civil and Mechaical Engineering, vol. 20, p. 20, 2020.

[6] N. Jeyaprakash, C. H. Yang, and S. Sivasankaran, "formation of FeCrMoVC layers on AA6061 by laser cladding process: microstructure and wear characteristics," Transactions of the Indian Institute of Metals, vol. 73, pp. 1611-1617, 2020.

[7] D. Zhang and X. Zhang, "Laser cladding of stainless steel with $\mathrm{Ni}-\mathrm{Cr} 3 \mathrm{C} 2$ and Ni-WC for improving erosive-corrosive wear performance," Surface and Coatings Technology, vol. 190, no. 2-3, pp. 212-217, 2005.

[8] L. J. da Silva and A. S. C. M. D’Oliveira, "NiCrSiBC coatings: effect of dilution on microstructure and high temperature tribological behavior," Wear, vol. 350-351, pp. 130-140, 2016.

[9] L. C. Lim, Q. Ming, and Z. D. Chen, "Microstructures of laserclad nickel-based hardfacing alloys," Surface and Coatings Technology, vol. 106, pp. 183-192, 1998.

[10] S. K. Albert, S. Venkadesan, and S. L. Mannan, "Studies on a nickel base hardfacing alloy deposited on stainless steel," in Proceedings of the Symposiyum On 'Joining of Materials for $2000 A D$, pp. 363-369, Indian Institute of Welding, Tiruchirapalli, India, December 1991.

[11] D. K. Dwivedi, "Adhesive wear behaviour of cast aluminium- silicon alloys: overview," Materials and Design, vol. 31, pp. 2517-2531, 2010.

[12] B. K. Prasad, "Structure-property related changes in hypoeutectic Al-Si alloys induced by solutionizing," Materials Transactions, JIM, vol. 34, pp. 873-881, 1994.

[13] D. K. Dwivedi, A. Sharma, and T. V. Rajan, "Friction and wear behaviour of hypereutectic Al-Si base alloys at low sliding velocities," Transactions of the Indian Institute of Metals, vol. 54 , pp. $247-254,2001$.

[14] R. K. Mahanti, K. Lal, A. N. Sinha, and C. S. Shivaramakrishanan, "A novel technique for hyper eutectic aluminium-silicon alloy melt treatment," Materials Transactions, JIM, vol. 34, pp. 1207-1211, 1993.

[15] K. Gurumoorthy, M. Kamaraj, K. Prasad Rao, A. Samba Siva Rao, and S. Venugopal, "Microstructural aspects of plasma transferred arc surfaced Ni-based hardfacing alloy," Materials Science and Engineering A, vol. 456, pp. 11-19, 2007.

[16] C. Sudha, P. Shankar, R. V. Subba Rao, R. Thirumurugesan, and M. Vijayalakshmi, "Baldev Raj, Microchemical and microstructural studies in a PTA weld overlay of $\mathrm{Ni}-\mathrm{Cr}-\mathrm{Si}-\mathrm{B}$ alloy on AISI 304L stainless steel," Surface and Coatings Technology, vol. 202, pp. 2103-2112, 2008.

[17] S. Gnanasekaran, G. Padmanaban, V. Balasubramanian, H. Kumar, and S. K. Albert, "Optimizing the laser parameters to attain maximum hardness in nickel based hardfacing surfaces," Journal of the Mechanical Behavior of Materials, vol. 26, no. 2-3, pp. 113-126, 2017.

[18] S. Gnanasekaran, G. Padmanaban, and V. Balasubramanian, "Effect of laser power on metallurgical, mechanical and tribological characteristics of hardfaced surfaces of nickel-based alloy," Lasers in Manufacturing and Materials Processing, vol. 4, no. 4, pp. 178-192, 2017.

[19] K. Gurumoorthy, M. Kamaraj, K. P. Rao, A. S. Rao, and S. Venugopal, Materials Science and Engineering A, vol. 456, pp. 11-19, 2007.

[20] I. Hemmati, V. Ocelík, and J. T. M. De Hosson, "Dilution effects in laser cladding of $\mathrm{Ni}-\mathrm{Cr}-\mathrm{B}-\mathrm{Si}-\mathrm{C}$ hardfacing alloys," Materials Letters, vol. 84, pp. 69-72, 2012. 
[21] 20.ASTM G 99 - 04, Standard Test Method for Wear Testing with a Pin-On-Disk Apparatus, ASTM International, West Conshohocken, PA, USA, 2016.

[22] I. Hemmati, Laser-Deposited Metallic Coatings: Processing, Characterization, Alloy Development, Ph.D Thesis, University of Groningen, Groningen, Netherlands, 2013.

[23] Q. Ming, L. C. Lim, and Z. D. Chenc, "Laser cladding of nickel-based hardfacing alloys," Surface and Coatings Technology, vol. 106, pp. 174-182, 1998.

[24] H. Zhang, Y. Shi, M. Kutsuna, and G. J. Xu, "Laser cladding of Colmonoy 6 powder on AISI316L austenitic stainless steel," Nuclear Engineering and Design, vol. 240, no. 10, pp. 26912696, 2010.

[25] D. C. Montgomery, Design and Analysis of Experiments, Wiley, Hoboken, NJ, USA, 2004.

[26] K. Y. Benyounis and A. G. Olabi, "Optimization of different welding processes using statistical and numerical approaches a reference guide," Advances in Engineering Software, vol. 39, no. 6, pp. 483-496, 2008.

[27] C. Samson Jerold Samuel, K. Murugan, A. P. Ray, M. Upadhyaya, V. Narasimharaj, and S. Gnanasekaran, "Optimization of process parameters using response surface methodology: a review," Materials Today: Proceedings, vol. 37, no. 2, pp. 1301-1304, 2021.

[28] S. Gnanasekaran, S. Senthil Kumar, N. raj Venugopal et al., "Effect of laser power on microstructure and tensile properties of pulsed Nd:YAG laser beam welded AISI 301 austenitic stainless steel joints," Materials Toda': Proceedings, vol. 37, no. 2, pp. 934-939, 2021.

[29] M. Qian, L. C. Lim, Z. D. Chen, and W. I. Chen, "Parametric studies of laser cladding processes," Journal of Materials Processing Technology, vol. 63, no. 1-3, pp. 590-593, 1997.

[30] A. I. Khuri and J. A. Cornell, Response Surfaces: Designs and Analyses, Rouledge, Oxford, England, 2nd edition, 1996.

[31] S. Gnanasekaran, G. Padmanaban, and V. Balasubramanian, "Effect of laser hardfacing process parameters on microstructural characteristics and microhardness of $\mathrm{Ni}-\mathrm{Cr}-\mathrm{B}-\mathrm{Si}-\mathrm{C}$ deposit on austenitic stainless-steel substrate," Journal of Advanced Microscopy Research, vol. 12, no. 3, pp. 173-181, 2017.

[32] S. Gnanasekaran, G. Padmanaban, V. Balasubramanian, H. Kumar, and S. K. Albert, "Correlation between travel speed, microstructure, mechanical properties and wear characteristics of Ni-based hardfaced deposits over 316LN austenitic stainless steel," High Temperature Materials and Processes, vol. 38, pp. 16-29, 2019.

[33] G. S. Padmanaban and V. Balasubramanian, H. Kumar and S.K. Albert, Laser hardfacing of colmonoy-5 (Ni-Cr-Si-B-C) powder onto 316LN austenitic stainless steel: effect of powder feed rate on microstructure," Mechanical Properties and Tribological Behavior" Lasers in Engineering, vol. 42, no. 4-6, pp. 283-302, 2019.

[34] G. Padmanaban and V. Balasubramanian, "Optimization of laser beam welding process parameters to attain maximum tensile strength in AZ31B magnesium alloy," Optics \& Laser Technology, vol. 42, no. 8, pp. 1253-1260, 2010.

[35] J. D. Majumdar and I. Manna, Laser-Assisted Fabrication of Materials, Springer Series in Materials Science, New York, NY, USA, 2012.

[36] D. Kesavan and M. Kamaraj, "The microstructure and high temperature wear performance of a nickel base hardfaced coating," Surface and Coatings Technology, vol. 204, no. 24, pp. 4034-4043, 2010. 